\title{
BIOVIOLÊNCIA E GESTÃO DOS CORPOS: UM ESTUDO EM GIORGIO AGAMBEN E ANTONIO NEGRI
}

\author{
Bioviolence and the Management of Bodies: a Study in Giorgio Agamben and Antonio Negri
}

\author{
Guilherme Brito de Primo *
}

\begin{abstract}
Resumo: Nosso trabalho tem por escopo problematizar as relações de poder que se afirmam mediante o uso biopolítico da violência, a partir da aproximação conceitual entre dois teóricos do biopoder que, divergentes em sua apreensão da noção foucaultiana, identificam um mesmo momento histórico, ora como paradigma, ora como sintoma de processos latentes: por um lado, Giorgio Agamben procura designar o biopoder a partir do entrecruzamento, no corpo da vida nua (em seus diversos codinomes), entre o jurídico e o político, através da decisão soberana que, atuando num patamar de indefinição, insere a vida em seu dispositivo de exceção mediante uma inclusão exclusiva na ordem jurídica. De outra forma, Antonio Negri observa o estado de exceção como um momento implícito no processo de expansão do capitalismo, no qual o declínio da soberania do Estado-nação materializa, por sua vez, o emergir do Império a partir da união entre categorias jurídicas e valores éticos universais, como os direitos humanos, designando uma supranacionalidade jurídica que encontra no estado de exceção um de seus principais eixos de atuação. A partir do referencial teórico, pretendemos demonstrar que a violência, operando no terreno da exceção, tanto através de seus aspectos "negativos", como uma tanatopolítica, quanto como regime de biopoder, administrando e regulando o espaço e as subjetividades, a partir de suas características positivas e constituintes, aparece, então, como um dispositivo de biopoder, ou uma bioviolência, que encontra no medo e na imagem do Inimigo suas principais fontes de legitimação.
\end{abstract}

Palavras-chave: Giorgio Agamben, Antonio Negri, Biopoder, Violência, Inimigo.

\begin{abstract}
Our work aims to identify the power relations affirmed through the biopolitical use of violence, starting from the conceptual approach between two biopower theorists who, although divergent in their apprehension of the Foucaultian notion, identify a same historical moment, sometimes as a paradigm, sometimes as a symptom of latent processes: on the one hand, Giorgio Agamben seeks to designate biopower from the interbreeding, in the body of naked life, or bare life (in its various codenames), between the legal and the political, through the sovereign decision that, acting in a level of indefinition, inserts the life in its exception's dispositif intending a exclusiveinclusion in the legal order. Otherwise, Antonio Negri observes the state of exception as an implicit moment in the process of expansion of capitalism, in which the decline of the sovereignty of the nation-state materializes, in turn, the emergence of Empire from the union between legal and universal ethical values, such as human rights, designating a legal supranationality that finds in the state of exception one of its main lines of action. Based on the theoretical framework, we intend to demonstrate that violence, operating in the field of exception, both through its "negative" aspects, as a tanatopolitics, and as a regime of biopower, admnistering and regulating space and subjectivities, from their positive and constituents characterists, then apperars as a biopower's dispositif, or bioviolence, which finds in the fear and image of Enemy it mais sources of legitimation. Keywords: Giorgio Agamben, Antonio Negri, Biopower, Violence, Enemy.
\end{abstract}

\footnotetext{
* Mestrando em Filosofia da Pontifícia Universidade Católica do Rio Grande do Sul. Bolsista CAPES. Endereço eletrônico: guiprimo_@hotmail.com.
}

\begin{tabular}{|c|c|c|c|c|c|}
\hline intuitio & $\begin{array}{c}\text { ISSN } \\
1983-4012\end{array}$ & Porto Alegre & Vol.11- $\mathrm{N}^{\mathrm{o}} .2$ & $\begin{array}{c}\text { Dezembro } \\
2018\end{array}$ & p.123-136 \\
\hline
\end{tabular}


Presenciamos um momento histórico marcado pelo medo. Progressivamente o espaço urbano ganha contornos murados e gradeados, protegidos por arames farpados e câmeras de segurança; vigilantes, patrulhas e incansáveis sentinelas fardados e municiados; verdadeiras táticas de guerra implementadas e, paulatinamente, naturalizadas no cotidiano tanto das grandes metrópoles, como das médias e pequenas cidades. A capitalização do medo e da violência toma, pouco a pouco, seu espaço no mercado, banalizando o consumo de serviços e apetrechos securitários que passam a dividir espaço no carrinho de compras e nas despesas do mês; itens corriqueiros, como uma bolsa ou um celular, incorporam, cada vez mais, dispositivos de rastreamento e mecanismos de segurança sofisticados. De modo geral, toda uma normalização do medo e da violência, toda uma estética de guerra e de militarização, perpassam, de forma banalizada, a rotina da sociedade. Ao mesmo tempo, o espaço privado absorve características que, outrora, pertenciam ao espaço público ${ }^{1}$. Shoppings, atualmente, tornaram-se o lazer principal aos finais de semana: passeios com a família, encontros com os amigos, feiras, eventos culturais, toda uma gama de atividades que, num outro período, aconteciam ao ar livre, nas ruas e nos parques da cidade, hoje inseridos, de forma cada vez mais acentuada, no espaço fechado e envidraçado dos grandes centros comerciais. Mesmo o interior de tais invólucros assume contornos paisagísticos, dotando o ambiente privado com aspectos naturais, espaços verdes, jardins e folhagens, chafarizes e demais símbolos que naturalizem o consumo, remetendo-o a uma atividade como outra qualquer, como um passeio no parque ou uma caminhada ao ar livre. Não por outro motivo, empreendimentos imobiliários, como residências e condomínios, adquirem, atualmente, uma arquitetura integrada e indiscernível, v.g., "hubs" e "trend centers", em cuja amorfia não podemos identificar e delimitar aquilo que constitui um mercado, uma loja, um hospital ou um apartamento: a vida, de maneira geral, encontra-se capitalizada, inserindo-se num processo gradual de integração em espaços privados e comerciais.

Observamos, portanto, o desenvolvimento e a comercialização de uma nova forma de vida, centrada e organizada a partir de tais espaços fechados, vigiados e gradeados, protegidos e cercados vinte e quatro horas por dia; toda uma dinâmica securitária que busca gerenciar a vivência (ou a sobrevivência) em zonas privadas e reclusas, ainda que verdejantes e coloridas.

1 ROLNIK, R. Guerra dos lugares: a colonização da terra e da moradia na era das finanças. $1^{\mathrm{a}}$ edição. São Paulo: Boitempo, 2015.

\begin{tabular}{|c|c|c|c|c|c|}
\hline intuitio & $\begin{array}{c}\text { ISSN } \\
1983-4012\end{array}$ & Porto Alegre & Vol.11 $-\mathrm{N}^{\circ} .2$ & $\begin{array}{c}\text { Dezembro } \\
2018\end{array}$ & p.123-136 \\
\hline
\end{tabular}


Toda uma pretensa aparência de natureza e naturalidade, cujas raízes não escondem, ou não poderiam esconder, o peso da violência originária que lhes precede: se, parafraseando Walter Benjamin, "nunca houve um monumento da cultura que não fosse também um monumento da barbárie"2, não poderíamos nos furtar a identificar, no ode à vida capitalizada e em toda a arquitetura securitária que lhe circunda, portanto, os verdadeiros monumentos de uma cultura que esconde seus despojos do outro lado dos muros. A partir da utilização do medo e da violência como dispositivos de biopoder, gerenciando e administrando uma nova forma de vida, desenvolvendo, numa dimensão normalizadora, tal cultura securitária, poderíamos identificar, talvez, o emergir da violência, atualmente, como bioviolência.

\section{II}

Não apenas a violência do soberano em relação ao súdito, nem tampouco do Estado frente ao cidadão; não aquela violência como resposta, ou defesa, frente a uma alteridade, fundamentada e outorgada a partir de uma lógica binária amigo-inimigo. Diferentemente de uma gama de teorias que se propõem a estudar a violência, bem como a militarização da vida, através da análise do poder a partir de suas características negativas, cujos fundamentos encontram-se numa tanatopolítica do "fazer sobreviver"3, nossa pesquisa terá por escopo entender o funcionamento da violência também em sua dimensão normalizadora, gerenciadora de formas de vida. Dito de outro modo parece-nos essencial a análise da utilização do medo, da violência e do Inimigo como eixos de um dispositivo de biopoder, cuja característica fundamental identifica-se tanto no gerenciamento da sobrevida, bem como na criação e modulação de novas formas de vida, alicerçadas na guerra e na ação policial não tão somente a partir de certas propriedades negativas e tanáticas, demarcadoras e excludentes, mas, sobretudo e fundamentalmente, a partir de seus aspectos ativos e constituintes.

Conforme Giorgio Agamben, "o significado imediatamente biopolítico do estado de exceção como estrutura original em que o direito inclui em si o vivente por meio de sua própria suspensão aparece claramente na "military order""4, promulgada pelo presidente Bush, em novembro de 2001, a partir da qual está autorizada a "indefinite detention" e o processo diante de

2 BENJAMIN, W. Obras escolhidas. Magia e técnica, arte e política. São Paulo: Editora Brasiliense, 1996, p. 225. 3 AGAMBEN, G. O que resta de Auschwitz: o arquivo e a testemunha (Homo Sacer III). Tradução de Selvino J. Assmann. São Paulo: Boitempo, 2008, p. 155

4 AGAMBEN, G. Estado de exceção. Tradução de Iraci D. Poletti, 2ª edição. São Paulo: Boitempo, 2004.

\begin{tabular}{|c|c|l|l|c|c|}
\hline intuitio & $\begin{array}{c}\text { ISSN } \\
1983-4012\end{array}$ & Porto Alegre & Vol.11- $\mathrm{N}^{\circ} .2$ & $\begin{array}{c}\text { Dezembro } \\
2018\end{array}$ & p.123-136 \\
\hline
\end{tabular}


"military commissions" de cidadãos suspeitos de envolvimento em atividades terroristas. Para o autor, os atentados do 11/9, bem como a consequente proclamação de uma "guerra contra o terror”, demarcam um momento paradigmático na história da política ocidental, a partir do qual, "diante do incessante avanço do que foi definido como uma 'guerra civil mundial', o estado de exceção tende cada vez mais a se apresentar como paradigma de governo dominante na política contemporânea"5. Assim, definindo o biopoder a partir da exceção soberana e seu patamar de indistinção entre o que é política e o que é direito, bem como através da inclusão exclusiva da vida $n u a^{6}$ na ordem jurídica, Agamben parece indicar o estado de exceção como a história da prática política no século XX, ora afirmada como paradigma nos primeiros anos do novo milênio ${ }^{7}$. Contudo, "articular a questão não significa que o dia 11 de setembro mudou tudo." 8 De acordo com Antonio Negri, o significado paradigmático dos atentados terroristas apenas explicitou um processo "implícito e maduro na passagem de época da década anterior. Sem dúvida, todavia, depois do dia 11 de setembro tudo parece ter mudado: é uma afirmativa que o poder faz para si mesmo, como se tivesse sido obrigado a acelerar suas expressões em termos de comando e repressão." ${ }^{99}$ que surge, então, de substancialmente definidor e paradigmático, "é a conscientização, por parte de todos nós, de estarmos na guerra; aquilo que percebíamos de modo confuso nos anos 1990 agora é evidente." 10

Destarte, conforme Hardt \& Negri, seria antes na afirmação do Império como ordem mundial, a partir da união entre categorias jurídicas e valores éticos, que poderíamos entender o renovado interesse no conceito e eficácia da bellum justum, ou "guerra justa", frequentemente invocada no discurso de combate ao terrorismo ${ }^{11}$. Segundo o autor, "a transformação jurídica funciona como sintoma das mudanças da constituição material biopolítica de nossas sociedades. Essas mudanças dizem respeito não apenas à lei internacional e às relações internacionais, mas também às relações de poder no plano interno de cada país." ${ }^{2}$ Assim, na medida em que fazemos a crítica das novas formas da lei internacional, a partir do entendimento da formação de

5 AGAMBEN, G. Estado de exceção. Tradução de Iraci D. Poletti, $2^{a}$ edição. São Paulo: Boitempo, 2004., p. 13. 6 AGAMBEN, G. Homo sacer: o poder soberano e a vida nua I. Tradução de Henrique Burigo. $2^{a}$ edição. Belo Horizonte: Editora UFMG, 2010.

7 AGAMBEN, G. Estado de exceção. Tradução de Iraci D. Poletti, $2^{a}$ edição. São Paulo: Boitempo, 2004., p. 37.

8 NEGRI, A. Cinco lições sobre o Império. Tradução de Alba Olmi. Rio de Janeiro: DP\&A, 2003, p. 192.

9 NEGRI, A. Cinco lições sobre o Império. Tradução de Alba Olmi. Rio de Janeiro: DP\&A, 2003, p. 192.

10 NEGRI, A. Cinco lições sobre o Império. Tradução de Alba Olmi. Rio de Janeiro: DP\&A, 2003, p. 192.

11 WALZER, M. Just and unjust wars. New York: Basic Books, 1992, e WALZER, Michael. On fighting terrorirsm justly. In: International Relations, vol. 21, nº 4, 2007, pp. 480-484.

12 HARDT, M; NEGRI, A. Império. Tradução de Berilo Vargas, 4ª edição. Rio de Janeiro: Record, 2002, p. 28.

\begin{tabular}{|c|c|l|l|c|c|}
\hline intuitio & $\begin{array}{c}\text { ISSN } \\
1983-4012\end{array}$ & Porto Alegre & Vol.11- $\mathrm{N}^{\circ} .2$ & $\begin{array}{c}\text { Dezembro } \\
2018\end{array}$ & p.123-136 \\
\hline
\end{tabular}


uma supranacionalidade jurídica, de caráter ativo e constituinte, cuja transformação expressa a transição do direito soberano do Estado-nação para uma configuração global pós-moderna de direito imperial, "seremos ao mesmo tempo empurrados para o coração da teoria política do Império, onde o problema da primazia supranacional, sua fonte de legitimação, e sua prática, põe em evidência problemas políticos, culturais e, finalmente, ontológicos."13

A guerra justa, em seus resquícios, rastros exportados e continuamente reciclados, como sintoma de uma formação jurídica supranacional, consolidada após o 11/9 com a implementação de políticas securitárias destinadas à guerra ao terror, apenas revela um processo que, de todo modo, já estava implícito. "Em termos constitucionais, os processos de globalização já não são apenas um fato, mas também uma fonte de definições jurídicas que tende a projetar uma configuração única supranacional de poder político" ${ }^{14}$ : portanto, ainda que o capitalismo, desde o início, demonstre sua inerente expansividade, "a atenção adequada às dimensões universais ou universalizantes, $a b$ origine, do desenvolvimento do capitalismo não deve nos impedir de ver a ruptura ou a mudança da produção capitalista contemporânea e as relações globais de poder."15 Se, anteriormente, os Estados-nação capitalistas procuravam exercer um domínio imperialista sobre outros países e regiões do globo, atualmente não poderíamos deixar de notar, contudo, "que o que era conflito ou competição entre diversas potências imperialistas foi, num sentido essencial, substituído pela ideia de um poder único que está por cima de todas elas, que as organiza numa estrutura unitária"16 e as trata de acordo com uma noção comum de direito.

Nessa conjuntura, ao passo que uma configuração jurídica supranacional começa a consolidar-se, manifesta-se também uma forma supranacional de soberania $^{17}$ - um Império global, no qual as condições e a percepção sobre a natureza da guerra e da violência encontram necessidade de transformação. A guerra, que a partir da modernidade poderia ser definida como um conflito armado entre duas ou mais entidades políticas soberanas (Estados-nação), hoje

13 HARDT, M; NEGRI, A. Império. Tradução de Berilo Vargas, 4ª edição. Rio de Janeiro: Record, 2002, p. 28. 14 HARDT, M; NEGRI, A. Império. Tradução de Berilo Vargas, 4ª edição. Rio de Janeiro: Record, 2002, p. 27. 15 HARDT, M; NEGRI, A. Império. Tradução de Berilo Vargas, 4ª edição. Rio de Janeiro: Record, 2002, p. 26. 16 HARDT, M; NEGRI, A. Império. Tradução de Berilo Vargas, $4^{a}$ edição. Rio de Janeiro: Record, 2002, p. 17 Seguindo uma linha parecida, Hobsbawm argumenta que "o Estado territorial soberano, que é o elemento essencial da política, democrática ou qualquer outra, está hoje mais fraco do que nos períodos anteriores. O alcance e a efetividade das suas atividades são menores do que nos períodos anteriores. Seu controle sobre a obediência passiva e sobre os serviços ativos dos seus súditos ou cidadãos é declinante. Os dois séculos e meio de crescimento ininterrupto do poder, do alcance, das ambições e da capacidade de mobilizar os habitantes dos Estados territoriais modernos, qualquer que seja a sua natureza ou a ideologia dos seus regimes, parecem ter chegado ao fim." HOBSBAWM, E. Globalização, democracia e terrorismo. Tradução de José Viegas. São Paulo: Companhia das Letras, 2007, p. 126.

\begin{tabular}{|c|c|c|c|c|c|}
\hline intuitio & $\begin{array}{c}\text { ISSN } \\
1983-4012\end{array}$ & Porto Alegre & Vol.11 - No.2 & $\begin{array}{c}\text { Dezembro } \\
2018\end{array}$ & p.123-136 \\
\hline
\end{tabular}


parece assumir características diametralmente opostas. Não mais o conflito localizado, com adversários definidos e por um tempo determinado: se, anteriormente, o Estado-nação possuía um jus ad bellum (direito de ir à guerra) frente a ameaça de agressão que, de algum modo, poderia colocar em risco sua integridade territorial ou soberania política, a bellum justum contemporânea materializa-se em seu status de ação policial, no qual a guerra e o Inimigo são banalizados e tornados absolutos, e seus limites temporais e espaciais tornaram-se, por conseguinte, indeterminados. Não queremos dizer, contudo, que a guerra moderna tenha se caracterizado, materialmente, por uma delimitação bem marcada ou pelos meticulosos movimentos em um tabuleiro de xadrez, no qual os adversários, assim como suas ações, respeitavam os códigos e exerciam sua força apenas sobre espaços e corpos anteriormente demarcados: ela fora, e continua sendo, uma experiência radical de violência e barbárie - basta atentarmos, por exemplo, à série de gravuras realizadas por Francisco de Goya entre 1810 e 1815, intituladas "Los Desastres de la Guerra". Talvez hoje a guerra apareça, até mesmo, de forma um tanto quanto "disciplinada", na qual armas de alta precisão, soldados minuciosamente treinados e táticas rigorosamente equacionadas tomam seu lugar no campo de batalha. Isto posto, no entanto, na medida em que o paradigma imperial tende a abarcar a vida de uma ponta a outra, também a guerra passa a ser entendida não mais como momento excepcional, intervalo inevitável, entre um contínuo período de paz, mas ao contrário, como relação social permanente, constituindo, conforme Hardt \& Negri, um "regime de biopoder"18 e ensejando um novo discurso político.

\section{III}

Um dos sintomas de mudança da percepção sobre a guerra verifica-se no próprio emprego corrente do conceito, que pode designar atividades muito diferentes da guerra propriamente dita. "Em certos casos, as metáforas de guerra são aplicadas a formas de competição e a relações de força que em geral não envolvem violência letal ou derramamento de sangue, tais como os esportes, o comércio ou a política interna de um país." ${ }^{19}$ Mesmo a guerra contra a pobreza, retórica utilizada em diversos contextos sociais diferentes, tem por objetivo arregimentar forças nacionais, ainda que divergentes, em torno de um objetivo, em tese, comum. "No caso da guerra contra as drogas, contudo, que teve início na década de 1980, e ainda mais no caso da guerra contra o terrorismo deste início do século XXI, a retórica da guerra começa a adquirir um caráter

18 HARDT, M; NEGRI, A. Multidão. Tradução de Clóvis Marques. Rio de Janeiro: Record, 2005 , p. 34. 19 HARDT, M; NEGRI, A. Multidão. Tradução de Clóvis Marques. Rio de Janeiro: Record, 2005 , p. 34.

\begin{tabular}{|c|c|l|l|c|c|}
\hline intuitio & $\begin{array}{c}\text { ISSN } \\
1983-4012\end{array}$ & Porto Alegre & Vol.11- $\mathrm{N}^{\circ} .2$ & $\begin{array}{c}\text { Dezembro } \\
2018\end{array}$ & p.123-136 \\
\hline
\end{tabular}


mais concreto." ${ }^{20}$ Assim como no caso da guerra contra a pobreza, aqui tampouco os inimigos são apresentados como entidades concretas, específicas e individualizadas, e sim como "conceitos abstratos ou talvez um conjunto de práticas." 21 No entanto, "de maneira muito mais bem-sucedida que no caso da guerra contra a pobreza, esses discursos de guerra servem para mobilizar todas as forças sociais e suspender ou limitar as trocas políticas normais"22 Sua particularidade, a partir de então, reside no fato de que seus limites temporais e espaciais adentraram um patamar de indefinição, no qual segurança externa e segurança interna confundem-se, passando, assim, “das invocações metafóricas e retóricas da guerra para guerras reais contra inimigos indefinidos e imateriais." 23

Desse modo, para que possamos propor e desenvolver a noção de uma bioviolência em toda sua potencialidade faz-se necessária a compreensão das camadas conceituais que perpassam a definição de guerra contemporaneamente, em cuja disposição encontraremos os elementos de sua condição atual como regime de biopoder. Outrossim, a partir do empreendimento de uma genealogia do Inimigo, cuja configuração contemporânea, disseminada e em rede, expressa a transformação paradigmática do seu uso e discurso, bem como sua correlação com a nova definição de guerra, poderíamos compreender a bioviolência, em sua dimensão normalizadora e constituinte, como um dispositivo biopolítico, cuja característica principal reside na afirmação de relações de poder a partir da produção e reprodução da vida e suas formas, apoiada na emergência de um paradigma securitário que se fundamenta no medo e na imagem do Inimigo.

Não raro, as "guerras justas” do início do século XXI apresentam ressonâncias das antigas guerras religiosas, e sua fundamentação, por parte de importantes correntes das relações internacionais, com base na teoria do conflito das civilizações ${ }^{24}$ - o Ocidente contra o Islã - não está muito distante daquelas velhas exortações. Tudo indica que mais uma vez estamos diante da situação definida pelo lema "Cujus regio, ejus religio, ou seja, aquele que governa também determina a fé religiosa" 25 , na qual, "paralelamente à nova versão do conceito de guerra justa, surge também, como se poderia prever, o conceito afim de mal. Apresentar o inimigo como encarnação do mal serve para torná-lo absoluto, assim como à guerra contra ele, tirando-o da

20 HARDT, M; NEGRI, A. Multidão. Tradução de Clóvis Marques. Rio de Janeiro: Record, 2005, p. 35. 21 HARDT, M; NEGRI, A. Multidão. Tradução de Clóvis Marques. Rio de Janeiro: Record, 2005, p. 35. 22 HARDT, M; NEGRI, A. Multidão. Tradução de Clóvis Marques. Rio de Janeiro: Record, 2005, p. 35. 23 HARDT, M; NEGRI, A. Multidão. Tradução de Clóvis Marques. Rio de Janeiro: Record, 2005, p. 34. 24 HUNTINGTON, S. O choque de civilizações e a reconstrução da ordem mundial. Rio de Janeiro: Objetiva, 1997, e HUNTINGTON, S. The clash of civilizations? In: Foreing Affairs, vol. 72, n 3, 1993, pp. 22-49.

25 HARDT, M; NEGRI, A. Multidão. Tradução de Clóvis Marques. Rio de Janeiro: Record, 2005, p. 37.

\begin{tabular}{|c|c|l|l|c|c|}
\hline intuitio & $\begin{array}{c}\text { ISSN } \\
1983-4012\end{array}$ & Porto Alegre & Vol.11- $\mathrm{N}^{\circ} .2$ & $\begin{array}{c}\text { Dezembro } \\
2018\end{array}$ & p.123-136 \\
\hline
\end{tabular}


esfera política." ${ }^{26} \mathrm{Na}$ medida em que se trata de um Inimigo abstrato e ilimitado, a aliança de amigos também torna-se expansiva e, potencialmente, universal, pois, em princípio, toda a humanidade pode unir-se diante de um conceito ou prática abstrata como o terrorismo. "Não surpreende, assim, que o conceito de 'guerra justa' tenha voltado a se manifestar no discurso dos políticos, jornalistas e acadêmicos, especialmente no contexto da guerra contra o terrorismo e das diferentes operações militares promovidas em nome dos direitos humanos." ${ }^{27}$ No plano interno, tomando de exemplo o contexto brasileiro, as marcas da guerra justa também se fazem presentes, ainda que sob outros codinomes: a cargo da paz e da segurança, decretam-se, de maneira já mais ou menos corriqueira, medidas de cunho excepcional, como a de $\mathrm{n}^{\circ} 9.288$, de 16 de fevereiro de 2018, na qual o Presidente da República autoriza o uso das forças armadas com o intuito de "pôr termo ao grave comprometimento da ordem pública" no Estado do Rio de Janeiro. O combate ao tráfico de drogas, assim como a guerra contra o terror, comporta, em suas variáveis, o mesmo elemento de disseminação e configuração em rede do Inimigo na pós-modernidade, atrelando a absolutização do mal, indiscernível e abstrato, a um slogan de caráter universal. De igual modo, a criminalização de manifestações e movimentos sociais, paulatinamente implementada nos últimos anos no Brasil, desenha a figura do Inimigo à imagem do "vândalo", ou dos black-blocks, materializando, em seu espectro, os elementos legitimatórios e constituintes de um dispositivo securitário, cujo funcionamento opera sobre os eixos da violência e do medo.

A bioviolência, assim entendida, expressa a face "produtiva" do biopoder e da segurança, emprestando uma nova racionalidade à gestão dos corpos que são capturados pelo seu dispositivo. Atuando no âmago do paradigma imperial, a ele refere-se por meio de sua capacidade de erigir novas formas jurídicas, a posteriori, de acordo com seus resultados, caracterizando-se, assim, a partir de seu aspecto regulador, "graças à construção e à imposição de sua própria estrutura legal." ${ }^{28}$ Desta forma, o Império, como paradigma jurídico supranacional, procura "ampliar o domínio dos consensos que dão apoio a seu próprio poder" ${ }^{29}$, na medida em que, consolidando uma ordem jurídica que fundamenta a violência a partir de seus resultados, demonstra seu vigor "não com base na força, mas com base na capacidade de mostrar a força

26 HARDT, M; NEGRI, A. Multidão. Tradução de Clóvis Marques. Rio de Janeiro: Record, 2005, p. 37. 27 HARDT, M; NEGRI, A. Multidão. Tradução de Clóvis Marques. Rio de Janeiro: Record, 2005, p. 36. 28 HARDT, M; NEGRI, A. Multidão. Tradução de Clóvis Marques. Rio de Janeiro: Record, 2005, p. 45. 29 HARDT, M; NEGRI, A. Império. Tradução de Berilo Vargas, $4^{a}$ edição. Rio de Janeiro: Record, 2002, p.

\begin{tabular}{|c|c|l|l|c|c|}
\hline intuitio & $\begin{array}{c}\text { ISSN } \\
1983-4012\end{array}$ & Porto Alegre & Vol.11- $\mathrm{N}^{\circ} .2$ & $\begin{array}{c}\text { Dezembro } \\
2018\end{array}$ & p.123-136 \\
\hline
\end{tabular}


como algo a serviço do direito e da paz."30 Tanto intervenções militares internacionais de caráter "humanitário", operando, principalmente, sobre as "vozes acusmáticas"31 do terrorismo islâmico no Oriente Médio, bem como as medidas de cunho excepcional, adotadas no plano interno nacional, tanto no Brasil como nos demais Estados-nação ${ }^{32}$, demonstram aquilo que, talvez, represente um dos sintomas mais significativos do emergir jurídico imperial como novo paradigma dominante: o desenvolvimento de um direito de intervenção ${ }^{33}$.

Ainda que figurando no arsenal de instrumentos postos à disposição das Nações Unidas por sua Carta, tendo por objetivo manter a ordem internacional entre entidades soberanas, "a reconfiguração contemporânea desse direito representa um salto qualitativo." 34 Se, na antiga ordem internacional, Estados individuais soberanos ou o poder supranacional (ONU), intervinham na soberania de um outro Estado-nação, o faziam com o objetivo declarado de assegurar ou impor a aplicação de acordos globais voluntariamente contratados. Hoje, no entanto, autoridades supranacionais, legitimadas não por direito, mas por consenso, intervêm em nome de qualquer espécie de emergência e princípios éticos superiores. "O que está por trás dessa intervenção não é um permanente estado de emergência e exceção, mas um permanente estado de emergência e exceção justificado pelo apelo a valores essenciais de justiça." "35 No âmbito interno, de igual forma, tais medidas securitárias atendem ao chamado de ordem, operando seu dispositivo, geralmente, sobre camadas marginais e criminalizadas, e ampliando sua legitimação a partir de uma dimensão normalizadora, na qual não apenas a manutenção da ordem é exigida, mas, fundamentalmente, o condicionamento do ambiente de forma constante e ativa, através de ações militares e/ou policiais: seja nas cruzadas internacionais, a partir de intervenções militares e do programa de guerra ao terrorismo, abertamente declarado após o 11/9, seja nas ruas das grandes cidades, suas periferias, e tudo aquilo para além dos muros que contornam cada esquina,

30 HARDT, M; NEGRI, A. Império. Tradução de Berilo Vargas, $4^{\text {a }}$ edição. Rio de Janeiro: Record, 2002, p. 31 "[...] insultos vulgares, gritos meio animalescos que não se podem (ainda) atribuir a indivíduos visualmente identificados, e que assim adquirem uma poderosa dimensão espectral.” ŽIŽEK, S. Bem-vindo ao deserto do Real!: cinco ensaios sobre o 11 de setembro e datas relacionadas. Tradução de Paulo Cezar Castanheira. São Paulo: Boitempo Editorial, 2003.

32 "Por meio de sua transformação contemporânea da lei supranacional, o processo imperial de constituição tende direta ou indiretamente a penetrar e reconfigurar a lei interna dos Estados-nação, e dessa forma a lei supranacional poderosamente superdetermina a lei nacional.” HARDT, M; NEGRI, A. Império. Tradução de Berilo Vargas, $4^{a}$ edição. Rio de Janeiro: Record, 2002, p. 35.

33 HARDT, M; NEGRI, A. Império. Tradução de Berilo Vargas, $4^{a}$ edição. Rio de Janeiro: Record, 2002, p.

34 HARDT, M; NEGRI, A. Império. Tradução de Berilo Vargas, $4^{\text {a }}$ edição. Rio de Janeiro: Record, 2002, p.

35 HARDT, M; NEGRI, A. Império. Tradução de Berilo Vargas, $4^{a}$ edição. Rio de Janeiro: Record, 2002, p. 36, grifo dos autores.

\begin{tabular}{|c|c|c|c|c|c|}
\hline intuitio & $\begin{array}{c}\text { ISSN } \\
1983-4012\end{array}$ & Porto Alegre & Vol.11 $-\mathrm{N}^{\circ} .2$ & $\begin{array}{c}\text { Dezembro } \\
2018\end{array}$ & p.123-136 \\
\hline
\end{tabular}


o que se esconde, sob rastros de pó e sangue, é um mesmo direito de polícia fundamentado sobre o paradigma securitário; uma forma de biopoder que "encarna a missão de produzir e transformar a vida social em seu nível mais geral e global."36; uma mesma bioviolência que, gerindo os corpos e a vida, encontra na imagem do Inimigo, seja ele o árabe muçulmano ou o negro marginalizado, sua principal fonte de legitimação ${ }^{37}$.

A guerra, neste ponto, opera numa dimensão não apenas destrutiva, mas como fundação da política, a partir de seu poder de ordenamento, constituinte e teleológico, expressando e reafirmando a inversão foucaultiana segundo a qual "a política é a guerra continuada por outros meios" 38 , tendo por função reinserir e gerenciar, perpetuamente, uma relação de força que sirva de ancoragem à formação das relações de poder na sociedade. "Mas dizer que a guerra é a fundação da política significa considerar implícita uma passagem posterior, ou seja, reconhecer na guerra aquelas capacidades de produção da subjetividade que disciplina e controle possuíam." 39 Se, na tradição moderna, a guerra representava um interstício de conflito após o qual, através da paz, se revelaria a ordem, atualmente, no entanto, a ordem não nasce do fim da guerra, mas através de uma promoção contínua desta ${ }^{40}$, por meio de uma ação permanente na qual se aplicam as funções de disciplina e controle, nas quais o Inimigo, com efeito, deve ser “continuamente construído, inventado, paradoxalmente não pode ser vencido ou, se for vencido, é preciso logo que haja outro" ${ }^{4142}$, funcionando, assim, como eixo de um dispositivo de biopoder. Se a guerra, como fundação da política, "é ela mesma forma de biopoder"43, o tema da definição do Inimigo, não sob a lógica da pura alteridade, mas antes inserido nos processos constituintes através da violência, tornar-se-á, por sua vez, central ${ }^{44}$.

36 HARDT, M; NEGRI, A. Multidão. Tradução de Clóvis Marques. Rio de Janeiro: Record, 2005, p. 43.

37 "O que está sendo construído sobre as ruínas das torres gêmeas é um Império absoluto contra os fantasmas do Mal. O céu, depois de ter sido escurecido pela poeira da destruição, é atualmente atravessado pelos raios e trovões de um poder que esquece a necessidade de paz e democracia. NEGRI, A. De volta: abecedário biopolítico [entrevistas a Anne Dufourmantelle]. Tradução de Clóvis Marques. Rio de Janeiro: Record, 2006.

38 FOUCAULT, M. Em defesa da sociedade: curso no Collège de France (1975-1976). Tradução de Maria Ermantina Galvão. São Paulo: Martins Fontes, 1999, p. 22.

39 NEGRI, A. Cinco lições sobre o Império. Tradução de Alba Olmi. Rio de Janeiro: DP\&A, 2003, p. 187.

40 CLASTRES, P. Arqueologia da violência: ensaios de antropologia política. Tradução de Carlos Eugênio Marcondes de Moura. São Paulo: Editora Brasiliense, 1982.

41 NEGRI, A. Cinco lições sobre o Império. Tradução de Alba Olmi. Rio de Janeiro: DP\&A, 2003, p. 188.

42 "Depois da derrocada do comunismo nada pode representar ameaça ao capitalismo. Até mesmo o terrorismo islâmico não representa uma manifestação de poder semelhante que pudesse realmente ameaçar o sistema capitalista; este pode, inclusive, absorver esse terrorismo e transformá-lo em energias sistêmicas." HAN, B. Topologia da violência. Tradução de Enio Paulo Giachini. Petrópolis, RJ: Vozes, 2017, p. 246.

43 NEGRI, A. Cinco lições sobre o Império. Tradução de Alba Olmi. Rio de Janeiro: DP\&A, 2003, p. 188.

44 NEGRI, A. Cinco lições sobre o Império. Tradução de Alba Olmi. Rio de Janeiro: DP\&A, 2003, p. 188.

\begin{tabular}{|c|c|c|c|c|c|}
\hline intuitio & $\begin{array}{c}\text { ISSN } \\
1983-4012\end{array}$ & Porto Alegre & Vol.11 - No.2 & $\begin{array}{c}\text { Dezembro } \\
2018\end{array}$ & p.123-136 \\
\hline
\end{tabular}


Problemas de violência, problemas de democracia: conforme Pierre Dardot e Christian Laval, "o sistema neoliberal está nos fazendo entrar na era pós-democrática" ${ }^{45}$, momento no qual, a partir de sua instauração por forças e poderes que se apoiam uns nos outros em nível nacional e internacional - alicerçados em oligarquias burocráticas e políticas, empresas multinacionais, atores financeiros e grandes organismos econômicos internacionais -, e formando, portanto, uma coalizão de caráter supranacional que exerce influência direta sobre a política mundial, a tendência de desativação do jogo democrático, e até mesmo da política como atividade, acentuase cada vez mais. Neste contexto, a dimensão constituinte e moduladora da guerra expressa sua relevância:

uma crise permanente, que se apresente como funcional, útil para a geração de lucros a partir da produção de novos serviços e mercadorias, bem como à repressão necessária à manutenção do projeto político e econômico imposto em determinado Estado, não é mais uma negatividade, um desvio, e sim uma positividade cara ao modelo neoliberal. ${ }^{46}$

O estado de exceção, talvez mais do que demarcar o limite entre o profano e o sagrado, trata de "ocultar uma opção política por manobras e ações justificadas pela falsa urgência ou pelo falso caráter extraordinário do momento." 47

No momento em que o discurso bélico contra uma imagem abstrata, um Inimigo indefinido ou conjunto de valores entra em cena, encontrando nos direitos humanos o eixo correlato de um dispositivo de biopoder (para o qual a vida e as formas de vida da população adquirem importância fundamental), cuja materialização revela o entrecruzamento entre uma categoria jurídica e valores éticos, são as liberdades e a democracia que expressam, ironicamente, o estado trágico do momento histórico de sua afirmação. Os direitos humanos, que outrora designaram um discurso de divergência e rebeldia, aparecem, hoje, como o "mito realizado das sociedades pós-modernas" ${ }^{\prime 4}$, nas quais a legitimação de políticas de cunho excepcional que se fundamentam sobre a imagem do Inimigo, bem como “o 'estado de exceção', a suspensão das

45 DARDOT, P; LAVAL, C. A nova razão do mundo: ensaio sobre a sociedade neoliberal. Tradução de Mariana Echalar, $1^{\text {a }}$ edição. São Paulo: Boitempo, 2016, p. 8.

46 CASARA, R. Estado pós-democrático: neo-obscurantismo e gestão dos indesejáveis. $1^{\circ}$ edição. Rio de Janeiro: Civilização Brasileira, 2017, p. 12.

47 CASARA, R. Estado pós-democrático: neo-obscurantismo e gestão dos indesejáveis. $1^{\circ}$ edição. Rio de Janeiro: Civilização Brasileira, 2017, p. 13.

48 DOUZINAS, C. O fim dos direitos humanos. Tradutora Luzia Araújo. São Leopoldo: Unisinos, 2009, p. 25.

\begin{tabular}{|c|c|c|c|c|c|}
\hline intuitio & $\begin{array}{c}\text { ISSN } \\
1983-4012\end{array}$ & Porto Alegre & Vol.11 $-\mathrm{N}^{\circ} .2$ & $\begin{array}{c}\text { Dezembro } \\
2018\end{array}$ & p.123-136 \\
\hline
\end{tabular}


liberdades civis, o uso extensivo da tortura"49, estão de volta à agenda, afogando as vitórias, em nome da liberdade e da democracia (contra o terrorismo médio-oriental, bem como em nome da ordem e da paz nacional, contra o marginalizado e os eventuais inimigos internos) num lícito mar de sangue ${ }^{50}$.

Perambulamos, conforme Peter Pál Pelbart,

em meio a espectros do comum: a mídia, a encenação política, os consensos econômicos consagrados, mas igualmente as recaídas étnicas ou religiosas, a invocação civilizatória calcada no pânico, a militarização da existência para defender a 'vida' supostamente 'comum', ou, mais precisamente, para defender uma forma-de-vida dita 'comum'. ${ }^{51}$

O Oriente do Ocidente aparece, portanto, como um objeto fabricado -

daí porque o diálogo com esse Oriente concreto está fadado de antemão ao fracasso mais retumbante. Algo similar aconteceu com a loucura, tal como foi analisada por Foucault: também a psiquiatria não é o conhecimento objetivo da doença mental, mas a racionalização de uma dominação concreta, e a loucura que a psiquiatria conhece é um objeto construído a partir dessa dissimetria de base. ${ }^{52}$

A dissolução da alteridade na política contemporânea, diferentemente de uma lógica binária que "levava o Outro a seu extremo e depois o negava para constituir-se" 53 aponta para uma das características fundamentais da estruturação imperial, aproximando e integrando o outro a sua ordem, e então orquestrando "essas diferenças num sistema de controle, na administração de microconflitualidades. ${ }^{54}$ Os direitos humanos, como corolários de uma nova era, centrada no paradigma securitário, designam o slogan universal em cujo porão afetos de revolta são paulatinamente sequestrados por ícones militares, aparelhos de captura e de terror de toda $\operatorname{ordem}^{55}$. Com a banalização do Inimigo, a vida dissimula-se nos espectros do comum ${ }^{56}$ e da

49 DOUZINAS, C. O fim dos direitos humanos. Tradutora Luzia Araújo. São Leopoldo: Unisinos, 2009, p. 14. 50 DOUZINAS, C. O fim dos direitos humanos. Tradutora Luzia Araújo. São Leopoldo: Unisinos, 2009, p. 15.

51 PELBART, P. Vida capital: ensaios de biopolítica. $1^{\mathrm{a}}$ edição, $2^{\mathrm{a}}$ reimpressão. São Paulo: Iluminuras, 2011, p. 28. 52 PELBART, P. Vida capital: ensaios de biopolítica. $1^{a}$ edição, $2^{a}$ reimpressão. São Paulo: Iluminuras, 2011, p. $120-121$.

53 PELBART, P. Vida capital: ensaios de biopolítica. $1^{\text {a }}$ edição, $2^{\mathrm{a}}$ reimpressão. São Paulo: Iluminuras, 2011, p. 121.

54 PELBART, P. Vida capital: ensaios de biopolítica. $1^{\mathrm{a}}$ edição, $2^{\mathrm{a}}$ reimpressão. São Paulo: Iluminuras, 2011, p. 121.

55 PELBART, P. Vida capital: ensaios de biopolítica. $1^{\text {a }}$ edição, $2^{\mathrm{a}}$ reimpressão. São Paulo: Iluminuras, 2011, p. 135.

\begin{tabular}{|c|c|l|l|c|c|}
\hline intuitio & $\begin{array}{c}\text { ISSN } \\
1983-4012\end{array}$ & Porto Alegre & Vol.11- $\mathrm{N}^{\circ} .2$ & $\begin{array}{c}\text { Dezembro } \\
2018\end{array}$ & p.123-136 \\
\hline
\end{tabular}


integração, e a guerra, como característica estrutural do Império, ganha cada vez mais destaque sob as vitórias dos direitos humanos. "Sua aplicação universal e seu total triunfo parecem ser uma questão de tempo e de ajuste entre o espírito da época e uns poucos regimes recalcitrantes. Sua vitória não é outra que não o cumprimento da promessa iluminista de emancipação pela razão." ${ }^{27}$ Os direitos humanos são, assim, "a ideologia depois do fim, a derrocada das ideologias ou, para usar uma expressão em voga, a ideologia no "fim da história",58, e anunciam, do alto de sua glória, a pálida melancolia das ruínas do progresso que jazem sob seus pés.

O tratamento filosófico do tema da violência e dos direitos humanos, se não atrelado ao comprometimento de uma "profunda reconstituição histórica do 'deserto do Real' em que nos encontramos" $" 59$, estará precipuamente fadado ao enredo pré-fabricado de uma totalidade que se esconde entre exortações e louvores apaixonados à guerra como instrumento ético, e entre escombros e despojos que, a contrapelo, alguns poucos tentam restaurar na história contada dos vencedores. A problemática trazida como núcleo da presente pesquisa expressa sua relevância a partir do reconhecimento de que a guerra transformou-se, atualmente, numa relação social permanente, que tem por objetivo a inserção da violência num dispositivo de biopoder, intentando, a partir de então, modular o Real, transformando-o numa "coisa manobrável, através de infinitos instrumentos de convencimento, dos mais sutis e delicados - dedicados aos cérebros sofisticados ou às sensibilidades exaltadas - aos mais explícitos e grosseiros - dedicados à vida nua, ao que está para além de toda classificação" ${ }^{60}$, consolidando relações de poder e capitalizando a vida e suas formas através da incitação do medo ao Inimigo.

A guerra, como palco ontológico da produção contemporânea de subjetividades, merece, a nosso ver, especial atenção, a partir da sua identificação como um dispositivo biopolítico, ou uma bioviolência, que, inserida no paradigma imperial, busca gerenciar tanto a vida quanto a sobrevida, revelando, assim, o clamor dissimulado dos arautos dos direitos humanos e da guerra

56 “[...] o universo do lugar-comum social, transformado em um fátuo suceder-se de imagens - eventualmente desligáveis com uma leve pressão no botão do controle remoto - reduplica a racionalidade instrumental que se aninha em certas dimensões da realidade e dali coordena o todo segundo sua vontade." SOUZA, R Levinas e a ancestralidade do mal: por uma crítica da violência biopolítica. Porto Alegre: EDIPUCRS, 2012, p. 76.

57 DOUZINAS, C. O fim dos direitos humanos. Tradutora Luzia Araújo. São Leopoldo: Unisinos, 2009 , p. 20.

58 DOUZINAS, C. O fim dos direitos humanos. Tradutora Luzia Araújo. São Leopoldo: Unisinos, 2009 , p. 20.

59 SOUZA, R. Levinas e a ancestralidade do mal: por uma crítica da violência biopolítica, 2012, p. 78.

60 SOUZA, R. Levinas e a ancestralidade do mal: por uma crítica da violência biopolítica, 2012, p. 9

\begin{tabular}{|c|c|l|l|c|c|}
\hline intuitio & $\begin{array}{c}\text { ISSN } \\
1983-4012\end{array}$ & Porto Alegre & Vol.11- $\mathrm{N}^{\circ} .2$ & $\begin{array}{c}\text { Dezembro } \\
2018\end{array}$ & p.123-136 \\
\hline
\end{tabular}


contra um Inimigo abstrato. É no horizonte da urgência biopolítica de nossa condição que poderemos, talvez, encontrar a possibilidade do acontecimento que desenrede o corpo tanto de sua nudez absoluta, quanto de sua capitalização sutil; é no desabar dos muros que encontraremos, do outro lado, a face do progresso refletida nos restos da história, que, sob a capa do Inimigo, revelam nada mais que nosso próprio fracasso.

\section{Referências}

AGAMBEN, G. Homo Sacer: o poder soberano e a vida nua I. Tradução de Henrique Burigo, $2^{\mathrm{a}}$ edição. Belo Horizonte: Editora UFMG, 2014.

Estado de exceção. Tradução de Iraci D. Poleti, 2a edição. São Paulo: Boitempo, 2004.

. O que resta de Auschwitz: o arquivo e a testemunha (Homo Sacer III). Tradução de Selvino J. Assmann. São Paulo: Boitempo, 2008.

BENJAMIN, W. Magia e técnica, arte e política: ensaios sobre literatura e história da cultura. São Paulo: Brasiliense, 1994.

CASARA, R. Estado pós-democrático: neo-obscurantismo e gestão dos indesejáveis. $1^{a}$ edição. Rio de Janeiro: Civilização Brasileira, 2017.

CLASTRES, P. Arqueologia da violência: ensaios de antropologia política. Tradução de Carlos Eugênio Marcondes de Moura. São Paulo: Editora Brasiliense, 1982.

DARDOT, P; LAVAL, C. A nova razão do mundo: ensaio sobre a sociedade neoliberal. Tradução de Mariana Echalar, $1^{\text {a }}$ edição. São Paulo: Boitempo, 2016.

DOUZINAS, C. $O$ fim dos direitos humanos. Tradução de Luzia Araújo. São Leopoldo: Unisinos, 2009.

FOUCAULT, M. Em defesa da sociedade: curso no Collège de France (1975-1976). Tradução de Maria Ermantina Galvão. São Paulo: Martins Fontes, 1999.

. História da sexualidade 1: a vontade de saber. Tradução de Maria Thereza da Costa Albuquerque e J. A. Guilhon Albuquerque, $3^{a}$ edição. São Paulo: Paz e Terra, 2015.

HAN, B. Topologia da violência. Tradução de Enio Paulo Giachini. Petrópolis, RJ: Vozes, 2017.

HARDT, M; NEGRI, A. Império. Tradução de Berilo Vargas, $4^{a}$ edição. Rio de Janeiro: Record, 2001. . Multidão. Tradução de Clóvis Marques. Rio de Janeiro: Record, 2005.

HOBSBAWM, E. Globalização, democracia e terrorismo. Tradução de José Viegas. São Paulo: Companhia das Letras, 2007.

HUNTINGTON, S. O choque de civilizações e a recomposição da ordem mundial. Rio de Janeiro: Objetiva, 1997. The clash of civilizations? In: Foreing Affairs, vol. 72, $\mathrm{n}^{\circ} 3,1993$, pp. 22-49.

NEGRI, A. De volta: abecedário biopolítico. Rio de Janeiro: Record, 2006.

. Cinco lições sobre o Império. Tradução de Alba Olmi. Rio de Janeiro: DP\&A, 2003.

2016.

PELBART, P. Vida capital: ensaios de biopolítica. $1^{\text {a }}$ edição. São Paulo: Iluminuras, 2011.

ROLNIK, R. Guerra dos lugares: a colonização da terra e da moradia na era das finanças. $1^{\mathrm{a}}$ edição. São Paulo: Boitempo, 2015.

SOUZA, R. Levinas e a ancestralidade do mal: por uma crítica da violência biopolítica. Porto Alegre: EDIPUCRS, 2012.

WALZER, M. On fighting terrorism justly. In: International Relations, vol. 21, nº 4, 2007, pp. 480-484.

Just and unjust wars. New York: Basic Books, 1992.

ŽIŽEK, S. Bem-vindo ao deserto do real!: cinco ensaios sobre o 11 de setembro e datas relacionadas. Tradução de Paulo Cezar Castanheira. São Paulo: Boitempo Editorial, 2003.

\begin{tabular}{|c|c|c|c|c|c|}
\hline intuitio & $\begin{array}{c}\text { ISSN } \\
1983-4012\end{array}$ & Porto Alegre & Vol.11 $-\mathrm{N}^{\circ} .2$ & $\begin{array}{c}\text { Dezembro } \\
2018\end{array}$ & p.123-136 \\
\hline
\end{tabular}

